\title{
Parosmia Due to COVID-19 Disease: A 268 Case Series
}

\author{
Rasheed Ali Rashid ${ }^{1}$ Ameer A. Alaqeedy ${ }^{2} \cdot$ Raid M. Al-Ani $^{2}$ (B)
}

Received: 25 March 2021 / Accepted: 10 May 2021/Published online: 23 May 2021

(C) Association of Otolaryngologists of India 2021

\begin{abstract}
Although parosmia is a common problem in the era of the COVID-19 pandemic, few studies assessed the demographic and clinical aspects of this debilitating symptom. We aimed to evaluate the socio-clinical characteristics and outcome of various options of treatment of individuals with parosmia due to COVID-19 infection. The study was conducted at two main Hospitals in the Ramadi and Tikrit cities, Iraq, on patients with a chief complaint of parosmia due to COVID-19 disease. The study involved 7 months (August 2020-February 2021). Detailed demographic and clinical characteristics and treatment options with their outcome were recorded and analyzed. Out of 268 patients with parosmia, there were 197 (73.5\%) females. The majority were from age group $\leq 30$ years $(\mathrm{n}=188$, $70.1 \%)$, housewives $(\mathrm{n}=150,56 \%)$, non-smokers $(\mathrm{n}=222,82.8 \%)$, and associated with dysgeusia $(\mathrm{n}=207$, $77.2 \%)$ but not associated with nasal symptoms $(\mathrm{n}=266$, 99.3\%). All patients have complained of anosmia (89.9\%) or hyposmia $(10.1 \%)$. Troposmia was reported in the majority of participants. The majority of the patients were suffering from severe parosmia (65.7\%). Around 3 quarters of the cases were presented in $\leq 4$ months. Altered quality of life (AQL) was presented in $91.8 \%$ of subjects, and there
\end{abstract}

Raid M. Al-Ani

med.raed.alani2003@uoanbar.edu.iq

Rasheed Ali Rashid

rasheed672003@tu.edu.iq

Ameer A. Alaqeedy

ameer-alaqeedy@yahoo.com

1 Department of Surgery/Otolaryngology, College of Medicine, Tikrit University, Tikrit, Iraq

2 Department of Surgery/Otolaryngology, College of Medicine, University Of Anbar, Ramadi, Iraq was a significant association with the presence of dysgeusia and type and severity of parosmia. The smoking habit didn't show a significant association with AQL, the severity of parosmia, and the recovery rate. Most of the odor group was the most triggering stimuli eliciting parosmia, while, the sewage was the response odor in above $50 \%$ of the cases. The recovery rate was poor with olfactory training plus either tonics or local and systemic steroids. Parosmia due to COVID-19 infection is a common problem with poor results in the short-term treatment and follow-up. The AQL was seen in a greater proportion of patients and strongly associated with the presence of dysgeusia, type, and severity of parosmia.

Keywords Parosmia - COVID-19 - Quality of life · Olfactory dysfunction · Case series

\section{Introduction}

The chemosensory function has many advantages. Firstly, it has an important role in detecting and differentiating various types of foods and beverages. Secondly, the olfactory sense acts as an early warning device for determining to threaten objects in the environment like fires, fumes, and spoiled foods. Thirdly, it can help certain jobs which they depend on the normal function of the smell such as housewives, food tasters, professional beverage, cockers, and firefighters. Lastly, any olfactory disorder harms the quality of the life [1].

In the early stage of the current COVID-19 pandemic, many studies from various nations reported that smell abnormalities, including anosmia and hyposmia, are frequent features of this disease [2-6]. These symptoms may present alone or with other features of the disease [6]. As 
time progressed, parosmia constitutes another feature of the longstanding COVID-19 infection. Abnormalities of the smell are usually not associated with other nasal symptoms like nasal obstruction and rhinorrhea [7].

Olfactory disorders are divided into 2 types quantitative (anosmia and hyposmia) and qualitative (parosmia and phantosmia) [8]. Anosmia is a total loss of the smell, hyposmia is a decrease in the sense of smell, parosmia is a distortion of the smell in the presence of an existing stimulus, and phantosmia is a distortion of the smell in the absence of an existing stimulus [8]. Parosmia can be unpleasant (troposmia) or pleasant (euosmia). Usually, parosmia and phantosmia occur in association with quantitative smell disorders but on rare occasions, they might present alone [9].

Despite olfactory dysfunctions are common, the exact mechanisms are still not yet established. Anyhow, a higher rate of recovery might explain the local inflammation of the olfactory area on the roof of the nose (conductive theory). While persistent anosmia and parosmia might explain the neuronal invasion by the COVID-19 virus (neuronal mechanism) [10].

There is a diverse list of causes of olfactory disorders includes post-viral upper respiratory tract infections, head injuries, intracranial tumors, sinonasal pathologies, and neurodegenerative disorders like Parkinson's and Alzheimer's diseases. However, in certain cases, there is no identified cause [11].

Olfactory disorders before the covid-19 pandemic were largely unrecognized, and often underestimated by researchers. While, during the COVID-19 pandemic, about $52.73 \%$ of cases result in loss of smell [12], most of them show excellent recovery rate within a short period (less than 4 weeks) [5]. Parosmia is a debilitation condition in which usual olfaction is distorted and unpleasant. The triggering molecular stimuli for the parosmia are wellknown. As well as the possible mechanism is the miswiring of the olfactory neurons [13]. Few numbers of studies are concerned with parosmia due to COVID-19 disease as mentioned in the literature. Parosmia is a common problem as Hopkins et al. reported a prevalence of parosmia $43.1 \%$ [14]. Therefore, we sought to study this topic with large numbers of patients when compared to other studies [8]1514.

We aimed to assess the demographic, clinical characteristics, and outcome of different modalities of treatment of patients with parosmia due to COVID-19 disease.

\section{Patients and methods}

This prospective case series of patients with parosmia was conducted at Al-Ramadi Teaching Hospital and Tikrit General Hospital, Ramadi and Tikrit cities, Iraq. The study involved the period from 1st of August 2020 to 28th February 2021. Patients with proven COVID-19 by realtime polymerase chain reaction (PCR) with a history of parosmia were enrolled in the study. Informed consent was taken from every participant. The current study was approved by the Ethical Approval Committee of the University of Anbar (reference number 21, 15-3-2021).

The exclusion criteria included patients.

1. With parosmia due to other causes like head injuries and neurodegenerative diseases.

2. With age less than 10 years.

3. With phantosmia.

4. With casosmia.

5. Toxic chemical exposure.

6. Who didn't want to participate in the study.

7. With psychological disturbances.

8. Who lost of follow-up.

The authors assessed all patients for the whole duration of the present study. Information through a thorough history with physical examination and, when indicated, radiological and other special tests (computed tomographic scans for subjects with sinonasal pathologies and brain magnetic resonance imaging for subjects with neurological features) were taken. Routine assessments included otorhinolaryngological, neurological, and systemic examinations and assessment of the olfactory function.

Data concerning the age, gender, occupation, smoking habit, duration of the anosmia or hyposmia plus the duration of the parosmia, dysgeusia, nasal symptoms, triggering factors, altered quality of life (a decreased appetite or weight loss or psychological changes or disturbances in daily living), and modality of treatment were recorded. The treatment included systemic and local steroids and olfactory training or olfactory training and tonics. The fate of the condition depended on a one-month follow-up following the treatment (recovered or not).

Assessment of the smell included a self-reported response from the patients using a $0-10 \mathrm{~cm}$ visual analog score (VAS) to determine the severity. A score of 1-4 was considered mild, 5-7 moderate, and 8-10 severe.

The data were entered and analyzed using IBM SPSS (Statistical Package for the Social Sciences) version 25. The results were described in means \pm SD for the age of the patients and the duration of the olfactory dysfunctions. Independent T-Test was used to compare between the means. Besides, the other variables were presented in 
tables of the frequency and percentages. Pearson Chisquare test was used to compare the categorical variables. $P$ value at $<0.05$ was considered a statistically significant difference.

\section{Results}

The study reported 268 subjects with a chief complaint of parosmia. There were 197 (73.5\%) females, with a male to female ratio of $1 / 2.77$. The age of our patients was ranged from 10 to 60 years with a mean age of $27.74 \pm 7.010$ years and the majority of the patients belong to the age group $\leq 30$ years $(n=188,70.1 \%)$. The highest occupation was a housewife $(n=150,56 \%)$, while the least was butcher, gas station worker, and healthcare worker ( $\mathrm{n}=3,1.1 \%$ for each). A $222(82.8 \%)$ of the participants were non-smokers Table 1 . The duration of the quantitive olfactory dysfunction (anosmia and hyposmia) was ranged from 0.3 to 3 months with a mean duration of $1.391 \pm 0.4537$ months. All cases were preceded by either anosmia $(241,89.9 \%)$ or hyposmia $(n=27,10.1 \%)$. Over three-quarters of the patients were suffering from dysgeusia. Almost all subjects were without associated nasal symptoms $(99.3 \%)$. Troposmia was found in the majority of subjects $(\mathrm{n}=257,95.9 \%)$. The majority of the subjects were suffered from severe parosmia $(\mathrm{n}=176,65.7 \%)$, followed by moderate $(\mathrm{n}=76,28.3 \%)$, and the least mild form $(n=16,6 \%)$. The duration of the parosmia was ranged from 0.3 to 6 months with a mean duration of $3.434 \pm 0.4886$ months. Around three-quarters of the participants were presented in $\leq 4$ months. The majority $(\mathrm{n}=246,91.8 \%)$ were complained from alteration in the quality of life. There was a high statistically significant difference between the quality of life and dysgeusia $(p$ value $=0.008)$, type $(p$ value $=0.000)$, and severity ( $p$ value $=0.000)$ of parosmia, but the insignificant difference with other factors $(p$ value $>0.05)$ Table 1.

Table 2 shows no significant association between smoking and the severity and fate of parosmia ( $p$ value $>0.05$ ).

The most frequent trigger odor eliciting parosmia was most of the odors ( $\mathrm{n}=125,46.64 \%)$, and the least meat $(\mathrm{n}=27,46.64 \%)$ as shown in Fig. 1. Sewage odor was the most common response to the triggering stimuli $(\mathrm{n}=146$, $54.48 \%)$, while the least citrus odor $(\mathrm{n}=16,5.97 \%)$ Fig. 2.

Out of 205, there were 12 patients $(4.48 \%)$ who recovered by using olfactory training plus local and systemic steroids. While only $6(2.24 \%)$ patients out of 63 recovered by using olfactory training plus tonics. There was no statistically significant difference between the fate (recovered or not) of the parosmia and the two options of treatment that were used in the current study ( $p$ value $=0.309$ ) Fig. 3.

\section{Discussion}

Loss of smell is a well-established symptom of the COVID-19 disease, so much so that it can be used to diagnose the illness. While most people who suffer from olfactory dysfunction due to COVID-19 recover it quickly within four weeks for $79 \%$ of people [16]. But some with long COVID-19 smell disorders are detected unpleasant odors months after catching the virus [14]. Patients with the COVID-19 disease across my country and the world are reporting unpleasant changes to their sense of smell after a COVID-19 diagnosis. This differs from the loss of sense of smell and taste, which is a pretty common COVID-19 symptom. This study represented a large case series of COVID-19 patients with parosmia (268 patients) within a short period (7 months). The main outcomes of the current study were all patients were suffering from hyposmia (27, $10.1 \%$ ) or anosmia $(241,89.9 \%)$ before the development of parosmia, alteration in the quality of life in the majority of cases $(91.8 \%)$, and poor outcome at short-term follow-up with different modalities of treatment.

The daily perception of parosmia was unpleasant for the majority of our patients and was typically described as sewage, moldy socks, rotten eggs, citrus, and rotten meats. All patients could identify the triggering stimuli eliciting parosmia. The study revealed a single or multiple triggering stimuli in all patients. While the response to these stimuli in all cases was single. The main odorant triggers were most of the odors $(46.64 \%)$, perfume $(22.39 \%)$, any odor $(10.45 \%)$, frying smell $(10.45 \%)$, and meat (10.07\%). This finding (single response to single or multiple triggering stimuli) was consistent with the previous study by Bonfils et al. [1]. It is of utmost importance to consider this observation in a future study to understand the exact pathogenesis of the parosmia.

It is often to see patients suffering from parosmia in the early phases of resolution from quantitative olfactory dysfunction (anosmia and hyposmia), 2 to 3 months from the onset of COVID-19 disease [13]. The mean duration of parosmia from the point of disappearance of anosmia or hyposmia in our study was $3.434 \pm 0.4886$ months, which is slightly higher than Hopkins et al. study (2.5 months) [14]. However, the duration of parosmia in this and Hopkins et al. studies was much lower than Bonfils et al. study $(63.0 \pm 7.6$ months) [1]. This difference may be attributed to the difference in the causes of parosmia, COVID-19 disease in the current and Hopkins et al. studies, and the causes in Bonfils et al. study were upper respiratory tract infection (24 patients), sinonasal disease ( 8 patients), toxic 
Table 1 The relationship between socio-clinical characteristics and parosmia of 268 patients with COVID-19 disease

\begin{tabular}{|c|c|c|c|c|}
\hline \multirow[t]{2}{*}{ Variables } & \multicolumn{3}{|l|}{ Quality of life } & \multirow[t]{2}{*}{$p$ value } \\
\hline & Not altered & Altered & Total & \\
\hline Mean age \pm SD & $28.23 \pm 9.092$ & $27.70 \pm 6.815$ & & 0.736 \\
\hline Age groups & & & & 0.446 \\
\hline$\leq 30$ years & $17(9 \%)$ & $171(91 \%)$ & $188(70.1 \%)$ & \\
\hline$>30$ years & $5(20 \%)$ & $75(80 \%)$ & $80(29.9 \%)$ & \\
\hline Total & $22(8.2 \%)$ & $246(91.8 \%)$ & $268(100 \%)$ & \\
\hline Gender & & & & 0.931 \\
\hline Males & $6(8.5 \%)$ & $65(91.5 \%)$ & $71(26.5 \%)$ & \\
\hline Females & $16(8.1 \%)$ & $181(91.9 \%)$ & $197(73.5 \%)$ & \\
\hline Total & $22(8.2 \%)$ & $246(91.8 \%)$ & $268(100 \%)$ & \\
\hline Occupation & & & & 0.125 \\
\hline Housewife & $13(8.7 \%)$ & $137(91.3 \%)$ & $150(56 \%)$ & \\
\hline Worker & $6(18.8 \%)$ & $26(81.2 \%)$ & $32(11.9 \%)$ & \\
\hline Free job & $2(8.7 \%)$ & $21(91.3 \%)$ & $23(8.6 \%)$ & \\
\hline Butcher & $0(0 \%)$ & $3(100 \%)$ & $3(1.1 \%)$ & \\
\hline Teacher & $0(0 \%)$ & $27(100 \%)$ & $27(10.1 \%)$ & \\
\hline Policeman & $0(0 \%)$ & $7(100 \%)$ & $7(2.6 \%)$ & \\
\hline Gas station worker & $0(0 \%)$ & $3(100 \%)$ & $3(1.1 \%)$ & \\
\hline Student & $0(0 \%)$ & $20(100 \%)$ & $20(7.5 \%)$ & \\
\hline Healthcare worker & $1(33.3 \%)$ & $2(66.7 \%)$ & $3(1.1 \%)$ & \\
\hline Total & $22(8.2 \%)$ & $246(91.8 \%)$ & $268(100 \%)$ & \\
\hline Smoking & & & & 0.895 \\
\hline Yes & $4(8.7 \%)$ & $42(91.3 \%)$ & $46(17.2 \%)$ & \\
\hline No & $18(8.1 \%)$ & $204(91.9 \%)$ & $222(82.8 \%)$ & \\
\hline Total & $22(8.2 \%)$ & $246(91.8 \%)$ & $268(100 \%)$ & \\
\hline Quantitative OD & & & & 0.368 \\
\hline Anosmia & $21(8.7 \%)$ & $220(91.3 \%)$ & $241(89.9 \%)$ & \\
\hline Hyposmia & $1(3.7 \%)$ & $26(96.3 \%)$ & $27(10.1 \%)$ & \\
\hline Total & $22(8.2 \%)$ & $246(91.8 \%)$ & $268(100 \%)$ & \\
\hline Dysgeusia & & & & 0.008 \\
\hline Yes & $12(5.8 \%)$ & $195(94.2 \%)$ & $207(77.2 \%)$ & \\
\hline No & $10(16.4 \%)$ & $51(83.6 \%)$ & $61(22.8 \%)$ & \\
\hline Total & $22(8.2 \%)$ & $246(91.8 \%)$ & $268(100 \%)$ & \\
\hline Nasal symptoms & & & & 0.671 \\
\hline Presence & $0(0)$ & $2(100 \%)$ & $2(0.7 \%)$ & \\
\hline Abscent & $22(8.3 \%)$ & $244(91.7 \%)$ & $266(99.3 \%)$ & \\
\hline Total & $22(8.2 \%)$ & $246(91.8 \%)$ & $268(100 \%)$ & \\
\hline Type of parosmia & & & & 0.000 \\
\hline Troposmia & $14(5.4 \%)$ & $243(94.5 \%)$ & $257(95.9 \%)$ & \\
\hline Euosmia & $8(72.7 \%)$ & $3(27.3 \%)$ & $11(4.1 \%)$ & \\
\hline Total & $22(8.2 \%)$ & $246(91.8 \%)$ & $268(100 \%)$ & \\
\hline Severity & & & & 0.000 \\
\hline Severe & $5(2.8 \%)$ & $171(97.2 \%)$ & $176(65.7 \%)$ & \\
\hline Moderate & $3(3.9 \%)$ & $73(96.1 \%)$ & $76(28.3 \%)$ & \\
\hline Mild & $14(87.5 \%)$ & $2(12.5 \%)$ & $16(6 \%)$ & \\
\hline Total & $22(8.2 \%)$ & $246(91.8 \%)$ & $268(100 \%)$ & \\
\hline
\end{tabular}


Table 1 continued

\begin{tabular}{llll}
\hline Variables & Quality of life & $p$ value \\
\cline { 2 - 4 } & Not altered & Altered & Total \\
\hline $\begin{array}{l}\text { Mean duration of parosmia } \\
\text { Duration of parosmia }\end{array}$ & $3.060 \pm 1.5283$ & $3.467 \pm 1.4836$ & 0.220 \\
$\leq$ months & $18(9 \%)$ & $181(91 \%)$ & 0.397 \\
$>4$ months & $4(5.8 \%)$ & $65(94.2 \%)$ & $199(74.3 \%)$ \\
Total & $22(8.2 \%)$ & $246(91.8 \%)$ & $69(25.7 \%)$ \\
\end{tabular}

Table 2 The relationship between the smoking habit and the severity and fate of the parosmia in the 268 patients with COVID-19 disease.

\begin{tabular}{|c|c|c|c|c|}
\hline \multirow[t]{2}{*}{ Variable } & \multicolumn{3}{|l|}{ Smoking } & \multirow[t]{2}{*}{$p$ value } \\
\hline & Yes & No & Total & \\
\hline Severity & & & & 0.347 \\
\hline Severe & $34(73.9 \%)$ & $142(64 \%)$ & $176(65.7 \%)$ & \\
\hline Moderate & $9(19.6 \%)$ & $67(30.2 \%)$ & $76(28.4 \%)$ & \\
\hline Mild & $3(6.5 \%)$ & $13(5.8 \%)$ & $16(5.9 \%)$ & \\
\hline Total & $46(17.2 \%)$ & $222(82.8 \%)$ & $268(100 \%)$ & \\
\hline Fate & & & & 0.556 \\
\hline Recovered & $4(22.2 \%)$ & $14(77.8 \%)$ & $18(6.7 \%)$ & \\
\hline Not recovered & $42(16.8 \%)$ & $208(83.2 \%)$ & $250(93.3 \%)$ & \\
\hline Total & $46(17.2 \%)$ & $222(82.8 \%)$ & $268(100 \%)$ & \\
\hline
\end{tabular}

Fig. 1 The trigger odors for the parosmia in the 268 COVID-19 patients

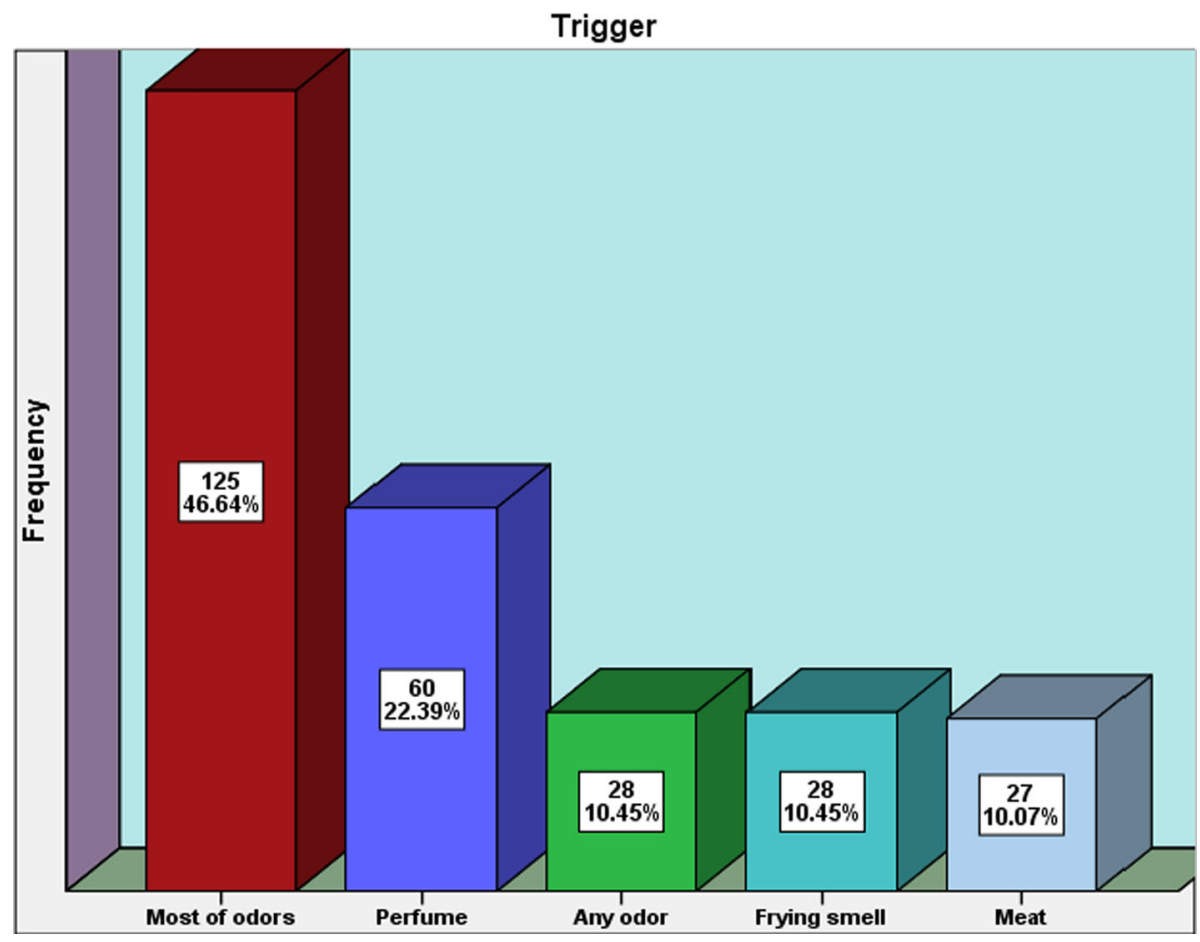


Fig. 2 The response odors in the 268 COVID-19 patients with parosmia
Fig. 3 The relationship between the treatment options and the fate of the COVID-19 patients with parosmia
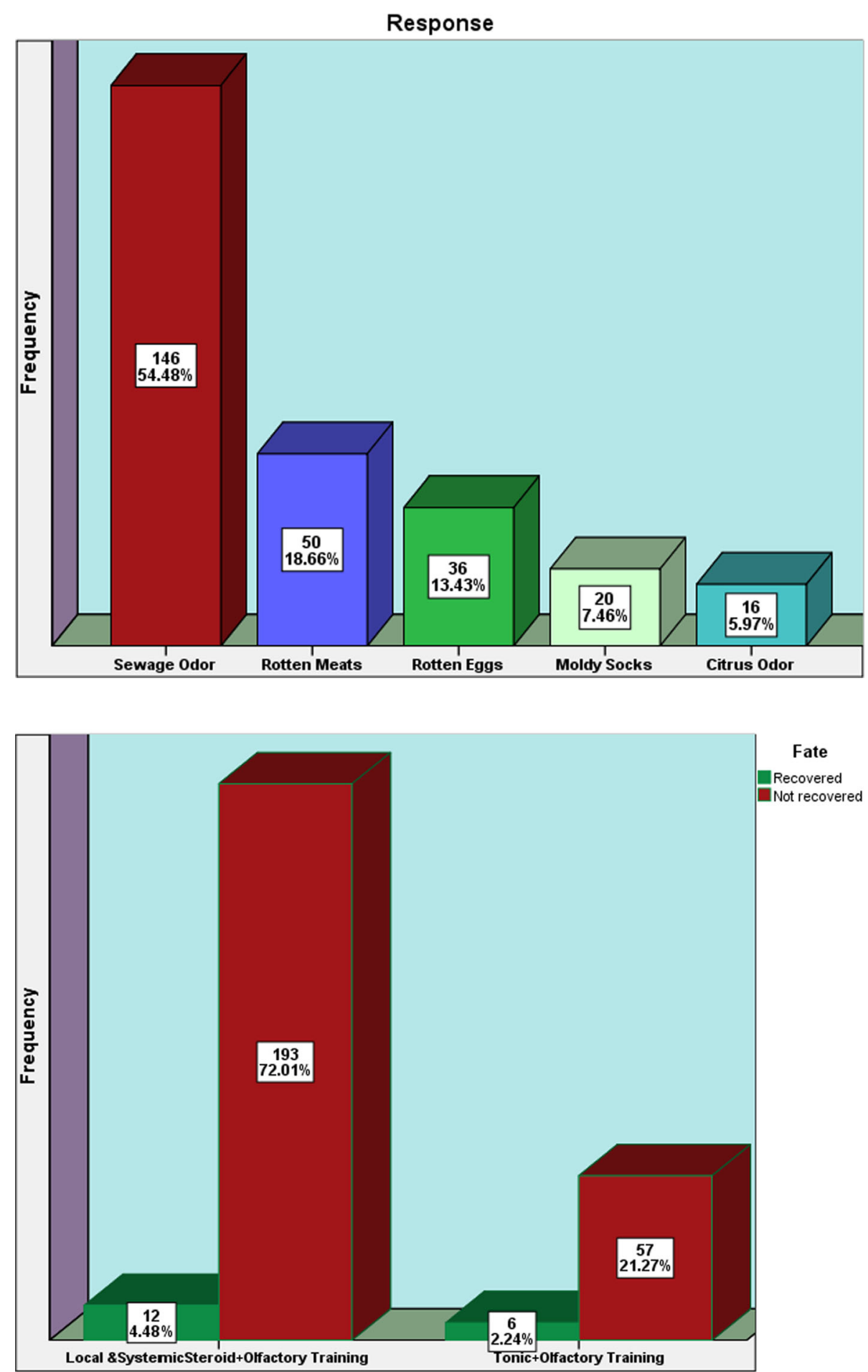

chemical exposure (4 patients), neurological disorders (3 patients), head injury (2 patients), nasal operation (2 patients), the aging process (1 patient), and idiopathic causes (12 patients). However, it is not known why patients with parosmia due to COVID-19 infection are present earlier than other causes of parosmia?. It is logical that the duration of parosmia greatly affects the quality of life, but, the present study didn't show such an association ( $p$ value $>0.05$ ). This contradiction might be due to the short period of parosmia and short-term follow-up in the study.

Quality of life was considered as altered if the patient reported a decrease in appetite or body weight or a change in mood. Alteration of the smell can affect the quality of 
life badly or may be a sign of more serious health problems. In the present study, $91.8 \%$ of the patients had altered daily life that agrees with other studies [17-21]. The study reported a highly statistically significant difference between the altered quality of life and the dysgeusia, type, and severity of parosmia. But there was no significant association between the quality of life and other studied variables.

The mean age of the patients with olfactory disorders was ranged from 35.91 to 57 years [15, 14, 22, 23]. Our result reported a lower mean of age than the above-mentioned studies. This may be attributed to the difference in the geographical area, ethnicity, and the cause of olfactory dysfunction. Besides, the current study revealed that about $75 \%$ of the cases were females, which was similar to other investigations [14], but in contrast to the prior study [5]. However, there was no significant difference ( $p$ value $>0.05$ ) between the age and gender and the state of the quality of life due to parosmia.

The job might be a risk factor for acquiring olfactory disorders. Lee et al. [24] from Korea reported a higher prevalence rate of olfactory disorders in certain jobs, automobile repair $(45.1 \%)$, printing $(69.7 \%)$, and shoemaking and plating $(88.9 \%)$ workers in comparison to the offices' workers $(21.2 \%)$. It is well-known that there is no one immune against the COVID-19 disease, but healthcare workers are more vulnerable [25]. The prior study by Villarreal et al. reported a high prevalence rate $(26 \%)$ of persistent olfactory dysfunction for more than one month among healthcare workers with COVID-19 infection [26], our study revealed that there were $3(1.1 \%)$ cases of the healthcare workers with parosmia. The study didn't find an explanation for this contradiction. The highest occupation affected in the present study was a housewife $(n=150$, $56 \%$ ). This may be attributed to the highest proportion of our patients were females (75\%). Moreover, this occupation carried a difficulty in cooking and difficulty in detecting the order of baby nappy. Besides, there was no statistically significant difference between the quality of life and the occupation in the current study ( $p$ value $>0.05)$.

Vent et al. study used the rat as a model for the assessment of the olfactory epithelium after exposure to tobacco smoke for 12 weeks, smoke and ethanol for the final 5 weeks, or no exposure to both of them (control group). Positive staining on the immunohistochemical analysis of the olfactory epithelium for the caspase-3 enzyme indicates the olfactory cells undergoing apoptotic proteolysis. They concluded that the loss of smell is higher in smokers than non-smoker owing to the increment in the death of the olfactory sensory neurons by cigarette smoke [27]. Hummel and Lötsch reported a significant negative impact of smoking on the recovery of smell disorders [28].
However, our study didn't find a significant effect of smoking on the severity of parosmia, quality of life alteration, and recovery rate.

Despite, the present study represented the largest case series study, there are limitations to this study. Firstly, the present study depends on the self-reported acquisition of the parosmia from the participants. Short-term follow-up of the cases is a second limitation, therefore we cannot determine the actual recovery rate of the parosmia in patients with the COVID-19 disease.

In conclusion, the current study revealed a large number of parosmia in patients with COVID-19 disease in a short period in comparison with other studies of the case series that involved the parosmia due to causes other than COVID-19. The majority of our cases were a young age group, females, housewives, and non-smokers. All cases were preceded by anosmia or hyposmia. The majority of the cases were also suffering from dysgeusia. The altered quality of life was significantly affected by the presence of dysgeusia, type, and severity of parosmia, while it was not affected by other factors (age, gender, occupation, smoking habit, duration of the parosmia, and whether the parosmia was preceded by quantitive olfactory disorders or associated with nasal symptoms). The outcome of both modalities of the treatment (olfactory training with either local and systemic steroid or tonics) was poor at the short-term follow-up.

Acknowledgements We extend our sincere thanks to all the ear, nose and throat surgeons at Al-Ramadi Teaching Hospital and Tikrit General Hospital for their cooperation in sending every patient to the authors who complains of parosmia after suffering from the COVID19 disease.

\section{Declarations}

Conflict of interest The authors declare that there is no conflict of interest.

\section{References}

1. Bonfils P, Avan P, Faulcon P, Malinvaud D (2005) Distorted odorant perception: analysis of a series of 56 patients with parosmia. Arch Otolaryngol Neck Surg 131(2):107-112

2. Vaira LA, Salzano G, Deiana G, De Riu G (2020) Anosmia and ageusia: common findings in COVID-19 patients. Laryngoscope. https://doi.org/10.1002/lary.28753

3. Gilani S, Roditi R, Naraghi M (2020) COVID-19 and Anosmia in Tehran, Iran. Med Hypotheses 21:109757

4. Meng X, Deng Y, Dai Z, Meng Z (2020) COVID-19 and anosmia: a review based on up-to-date knowledge. Am J Otolaryngol. https://doi.org/10.1016/j.amjoto.2020.102581

5. Al-Ani RM, Acharya D (2020) Prevalence of anosmia and ageusia in patients with COVID-19 at a primary health center, Doha, Qatar. Indian J Otolaryngol Head Neck Surg. https://doi.org/10.1007/s12070-020-02064-9 
6. Hopkins C, Surda P, Kumar N (2020) Presentation of new onset anosmia during the COVID-19 pandemic. Rhinology 58(3):295-298

7. Lechien JR, Chiesa-Estomba CM, De Siati DR, Horoi M, Le Bon SD, Rodriguez A, Dequanter D, Blecic S, El Afia F, Distinguin L, Chekkoury-Idrissi Y, Hans S, Delgado IL, Calvo-Henriquez C, Lavigne P, Falanga C, Barillari MR, Cammaroto G, Khalife M, Leich P, Souchay C, Rossi C, Journe F, Hsieh J, Edjlali M, Carlier R, Ris L, Lovato A, De Filippis C, Coppee F, Fakhry N, Ayad T, Saussez S (2020) Olfactory and gustatory dysfunctions as a clinical presentation of mild-to-moderate forms of the coronavirus disease (COVID-19): a multicenter European study. Eur Arch Otorhinolaryngol 277:2251-2261. https://doi.org/10.1007/s00405-020-05965-1

8. Yousefi-Koma A, Haseli S, Bakhshayeshkaram M, Raad N, Karimi-Galougahi M (2021) Multimodality imaging with PET/ $\mathrm{CT}$ and MRI reveals hypometabolism in tertiary olfactory cortex in parosmia of COVID-19. Acad Radiol. https://doi.org/10.1016/j.acra.2021.01.031

9. Hummel $\mathrm{T}$ et al (2017) Position paper on olfactory dysfunction. Rhinol Suppl 54:1-30

10. Iannilli E, Leopold DA, Hornung DE, Hummel T (2019) Advances in understanding parosmia: an fMRI study. Orl 81(4): 185-192

11. Liu DT et al (2021) Parosmia is associated with relevant olfactory recovery after olfactory training. Laryngoscope 131(3):618-623

12. Tong JY, Wong A, Zhu D, Fastenberg JH, Tham T (2020) The prevalence of olfactory and gustatory dysfunction in COVID-19 patients a systematic review and meta-analysis. Otolaryngol Neck Surg. https://doi.org/10.1177/0194599820926473

13. Parker JK, Kelly CE, Gane SB (2021) Molecular mechanism of parosmia, medRxiv, 2021. https://doi.org/10.1101/2021.02.05.21251085

14. Hopkins C et al (2020) Six month follow-up of self-reported loss of smell during the COVID-19 pandemic. Rhinology. https://doi.org/10.4193/Rhin20.544

15. Karimi-Galougahi M, Yousefi-Koma A, Bakhshayeshkaram M, Raad N, Haseli S (2020) 18FDG PET/CT scan reveals hypoactive orbitofrontal cortex in anosmia of COVID-19. Acad Radiol 27(7):1042-1043

16. Hopkins C, Surda P, Whitehead E, Kumar BN (2020) Early recovery following new onset anosmia during the COVID-19 pandemic-an observational cohort study. J Otolaryngol Neck Surg 49:1-6

17. Dl BW, Campbell M, Hopkins C, Smith B, Kelly C, Deary V (2020) Altered smell and taste anosmia, parosmia and the impact of long Covid-19. Altered Eat Res Netw. https://doi.org/10.1101/2020.11.26.20239152

18. Frasnelli J, Hummel $\mathrm{T}$ (2005) Olfactory dysfunction and daily life. Eur Arch Oto-Rhino-Laryngology Head Neck 262(3):231-235

19. Neuland C, Bitter T, Marschner H, Gudziol H, Guntinas-Lichius O (2011) Health-related and specific olfaction-related quality of life in patients with chronic functional anosmia or severe hyposmia. Laryngoscope 121(4):867-872

20. Miwa T, Furukawa M, Tsukatani T, Costanzo RM, DiNardo LJ, Reiter ER (2001) Impact of olfactory impairment on quality of life and disability. Arch Otolaryngol Neck Surg 127(5):497-503

21. Blomqvist EH, Brämerson A, Stjärne P, Nordin S (2004) Consequences of olfactory loss and adopted coping strategies. Rhinology 42(4):189-194

22. Kim DH et al (2017) Prognosis of olfactory dysfunction according to etiology and timing of treatment. Otolaryngol Neck Surg 156(2):371-377

23. Reden J, Maroldt H, Fritz A, Zahnert T, Hummel T (2007) A study on the prognostic significance of qualitative olfactory dysfunction. Eur Arch Oto-Rhino-Laryngol 264(2):139-144

24. Lee S-J, Kim E-M, Cho S-H, Song J, Jang T-W, Lee M-Y (2018) (2018) Risk of olfactory dysfunction of the workers in the automobile repair, printing shoemaking and plating industries in Korea: a cross-sectional study. BMJ Open 8(11):022678

25. Chirico F, Nucera G, Magnavita N (2020) COVID-19: protecting healthcare workers is a priority. Infect Control Hosp Epidemiol 41(9): 1117

26. Villarreal IM et al (2020) Olfactory and taste disorders in healthcare workers with COVID-19 infection. Eur Arch OtoRhino-Laryngol. https://doi.org/10.1007/s00405-020-06237-8

27. Vent $J$ et al (2004) Pathology of the olfactory epithelium: smoking and ethanol exposure. Laryngoscope 114(8):1383-1388

28. Hummel T, Lötsch J (2010) Prognostic factors of olfactory dysfunction. Arch Otolaryngol Neck Surg 136(4):347-351

Publisher's Note Springer Nature remains neutral with regard to jurisdictional claims in published maps and institutional affiliations. 